\title{
Abdominal varicosities secondary to inferior vena cava filter thrombosis
}

\author{
Raman Mehrzad
}

Department of Internal Medicine, Yale New Haven Hospital, Yale School of Medicine, New Haven, Connecticut, USA

\section{Correspondence to} Dr Raman Mehrzad, raman_m1@hotmail.com

Accepted 4 December 2015

\section{DESCRIPTION}

A 43-year-old man with a medical history of multiple deep vein thrombosis and right inferior vena cava (IVC) filter placement, was evaluated for shortness of breath and venous claudication. Vital signs showed an $\mathrm{O}_{2}$ saturation of $90 \%$ on room air and a respiratory rate of 24 breaths/min. Physical examination revealed grossly dilated veins of the abdomen, chest wall and inguinal areas (figure 1), as well as dilated veins in the patient's legs. Lung examination was notable for crackles in the left lower lobe. Given the elevated Wells' score, and clinical findings of shortness of breath and history of clots, a computer tomography of the patient's abdomen and chest was performed, which revealed

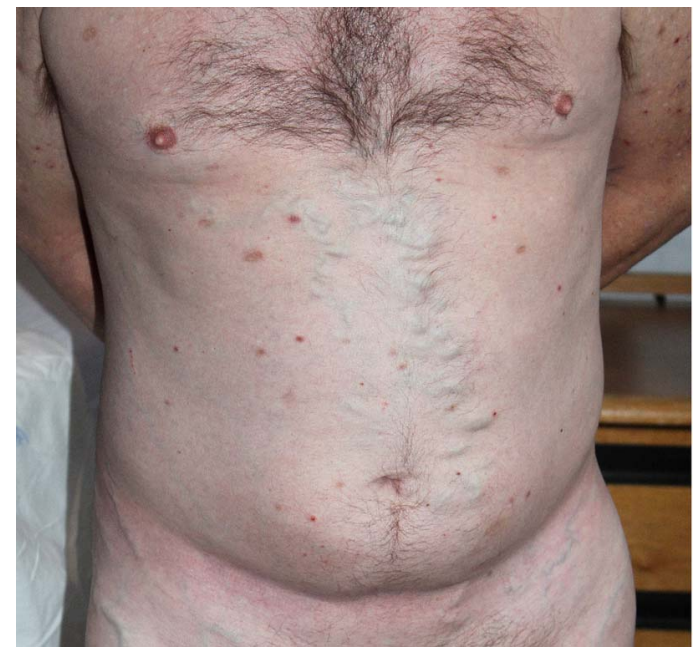

Figure 1 Varicosities and venous stasis of the superficial veins of the abdomen.

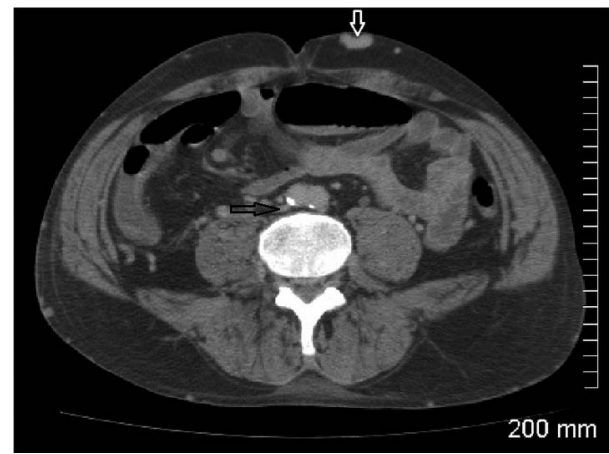

Figure 2 Axial image from a contrast-enhanced abdominal CT demonstrating a very small, occluded, flattened inferior vena cava (black arrow) and a large venous varix (white arrow) in the subcutaneous fat of the anterior abdominal wall.

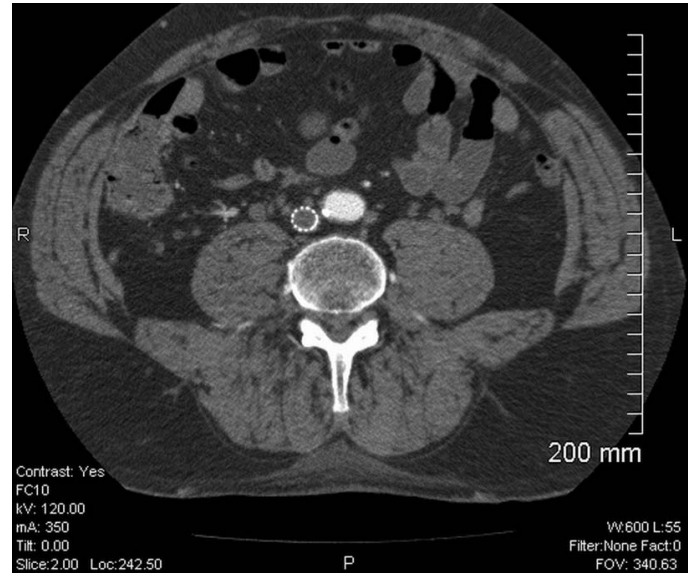

Figure 3 Axial contrast-enhanced CT images, with coronal and sagittal reconstructions, demonstrating a stent within the infrarenal inferior vena cava (IVC), previously placed to relieve an obstruction. An IVC filter is present cephalic to the stent.

a small and thrombosed IVC, with dilated superficial and intra-abdominal veins (figures 2-5). The patient was started on anticoagulants with low-molecular-weight heparin. His shortness of

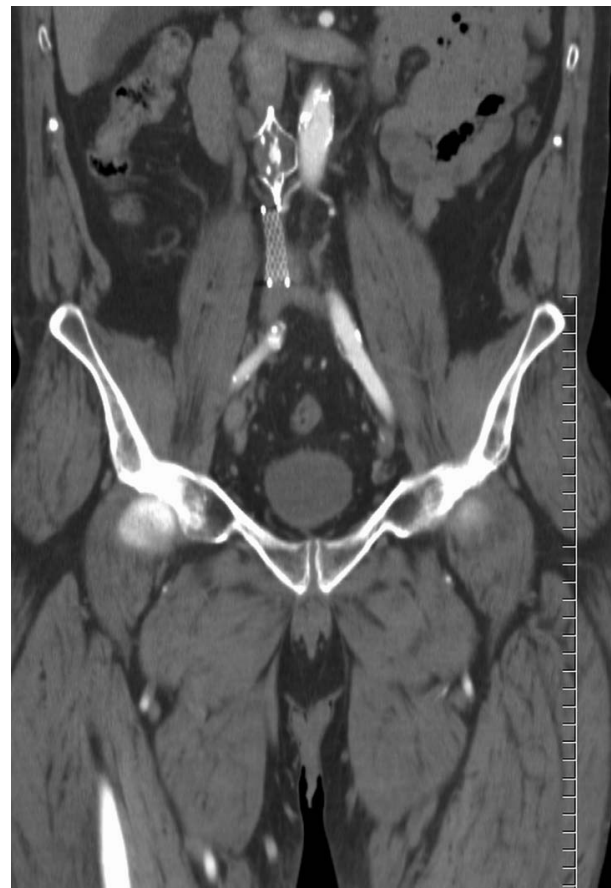

Figure 4 Axial contrast-enhanced CT images, with coronal and sagittal reconstructions, demonstrating a stent within the infrarenal inferior vena cava (IVC), previously placed to relieve an obstruction. An IVC filter is present cephalic to the stent. 


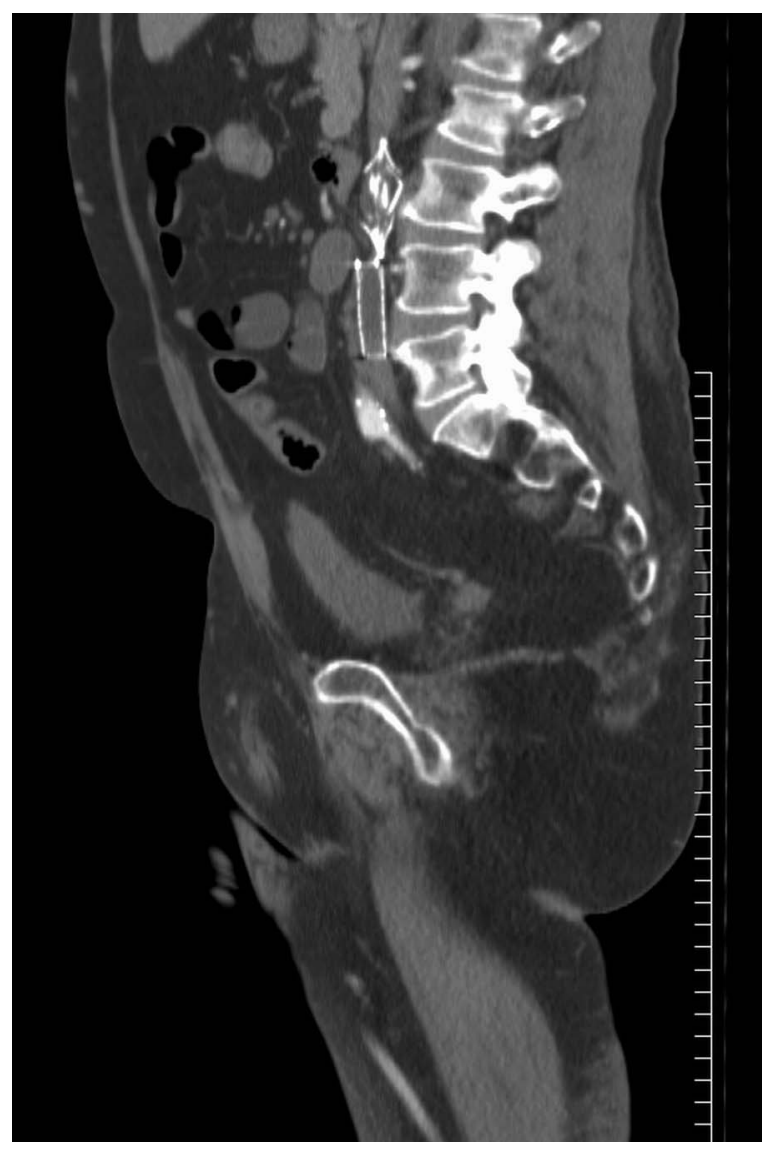

Figure 5 Axial contrast-enhanced $\mathrm{CT}$ images, with coronal and sagittal reconstructions, demonstrating a stent within the infrarenal inferior vena cava (IVC), previously placed to relieve an obstruction. An IVC filter is present cephalic to the stent.

breath was found to be secondary to a pneumonia. After discharge, he was later followed up by our vascular surgeons and underwent successful stenting.
Complete IVC obstruction from an IVC filter is a well-known complication, with signs and symptoms ranging from no symptoms to cardiovascular collapse. ${ }^{1}$ However, resultant varicosities and venous stasis of the superficial veins of the abdomen are rare. ${ }^{2}$ The pathophysiology is due to the increased thrombogenicity that occurs by placement of a filter. ${ }^{1}$ In the event of chronic occlusion, collateral pathways must be developed to maintain venous drainage. The lateral thoracic pathway uses the lateral thoracic, thoracoepigastric, superficial circumflex, long saphenous and femoral veins to collateralise to the IVC. ${ }^{3}$

\section{Learning points}

- Complete inferior vena cava (IVC) obstruction from an IVC filter is a well-known complication, however, resultant varicosities and venous stasis of the superficial veins of the abdomen are rare.

- Grossly dilated veins of the abdomen should raise suspicion of an IVF obstruction.

- The pathophysiology is due to the increased thrombogenicity that occurs by placement of a filter, similar to the result from placing any other foreign body.

Competing interests None declared.

Patient consent Obtained.

Provenance and peer review Not commissioned; externally peer reviewed.

\section{REFERENCES}

1 McAree BJ, O'Donnell ME, Fitzmaurice GJ, et al. Inferior vena cava thrombosis: a review of current practice. Vasc Med 2013;18:32-43.

2 Roncato C, Lefant PY. Images in clinical medicine. Thrombosis of the inferior vena cava and dilated veins of the trunk. N Engl J Med 2011;364:2535.

3 Kapur S, Paik E, Rezaie A, et al. Where there is blood, there is a way: unusual collateral vessels in superior and inferior vena cava obstruction. Radiographics 2010;30:67-78.

Copyright 2015 BMJ Publishing Group. All rights reserved. For permission to reuse any of this content visit

http://group.bmj.com/group/rights-licensing/permissions.

BMJ Case Report Fellows may re-use this article for personal use and teaching without any further permission.

Become a Fellow of BMJ Case Reports today and you can:

- Submit as many cases as you like

- Enjoy fast sympathetic peer review and rapid publication of accepted articles

- Access all the published articles

- Re-use any of the published material for personal use and teaching without further permission

For information on Institutional Fellowships contact consortiasales@bmjgroup.com

Visit casereports.bmj.com for more articles like this and to become a Fellow 